Journal de la Société des américanistes

Journal de la Société

des américanistes

\title{
Claude Lévi-Strauss (1908-2009), in memoriam
}

Philippe Erikson

\section{CpenEdition}

Journals

Édition électronique

URL : https://journals.openedition.org/jsa/17125

DOI : 10.4000/jsa. 17125

ISSN : 1957-7842

Éditeur

Société des américanistes

Édition imprimée

Date de publication : 20 décembre 2019

Pagination : 7-8

ISSN : 0037-9174

Référence électronique

Philippe Erikson, «Claude Lévi-Strauss (1908-2009), in memoriam», Journal de la Société des

américanistes [En ligne], 105-2 | 2019, mis en ligne le 20 décembre 2019, consulté le 03 septembre 2022. URL : http://journals.openedition.org/jsa/17125; DOI : https://doi.org/10.4000/jsa. 17125

Tous droits réservés 


\section{Claude Lévi-Strauss (1908-2009), in memoriam}

À l'occasion du dixième anniversaire de sa disparition, le Journal de la Société des américanistes se tenait d'honorer la mémoire de cette figure majeure de l'anthropologie du Xxe siècle qu'aura été Claude Lévi-Strauss. Pour ce faire, plutôt que de rajouter des gloses supplémentaires à la myriade déjà produites au cours des dernières décennies, la rédaction a choisi de mettre l'accent sur quelques volets encore inédits d'une œuvre qui n'a décidément pas fini de nous livrer toute sa richesse.

Proposé par Emmanuel Désveaux, le premier volet de cet hommage présente son ambitieux projet de déchiffrage, numérisation et réédition critique des carnets de l'expédition menée par Claude Lévi-Strauss chez les Nambikwara de mai 1938 à janvier 1939. Si cette mission est surtout connue par la relation qui en a été faite en 1955 dans Tristes Tropiques, le JSA peut s'enorgueillir d'avoir eu, dès 1948, la primeur de ses résultats scientifiques ${ }^{1}$. Contrairement à la précédente qui portait sur les Bororo $(1936)^{2}$, cette seconde contribution majeure de Lévi-Strauss au Journal de la Société des américanistes ne mettait toutefois guère à l'honneur ses talents de dessinateur. En guise de clin d'œil, sinon de compensation rétrospective, le croquis inédit choisi pour orner la couverture de la présente livraison a précisément été extrait des manuscrits nambikwara conservés à la BNF. Il est reproduit avec l'aimable autorisation des ayants droit.

Le second texte que nous proposons est celui d'un entretien à ce jour inédit où Lévi-Strauss essuie le feu nourri de trois interlocuteurs passionnés. Il fut réalisé en 1978 comme galop d'essai pour un ouvrage que l'éditeur Pierre Bérès avait prévu de réaliser à partir d'une série d'interviews subséquentes,

1. Claude Lévi-Strauss, «Contribution à l'étude de l'organisation sociale des Indiens Bororo », Journal de la Société des américanistes, 28, 1936, p. 269-304.

2. Claude Lévi-Strauss, « La vie familiale et sociale des Indiens Nambikwara », Journal de la Société des américanistes, 37, 1948, p. 1-132. 
qui n'eurent cependant jamais lieu. Lévi-Strauss, de son propre aveu, gardait un mauvais souvenir de cette session, et son agacement transparaît clairement dans la transcription des prolégomènes de ce projet qui ne vit jamais le jour. C'est d'ailleurs un des intérêts de ce texte, qui montre un Lévi-Strauss quelque peu bousculé par des intervieweurs moins déférents que d'habitude, et auxquels il répond avec une revigorante lucidité.

Dans un courrier adressé à la rédaction, Monique Lévi-Strauss, qui avait assisté à cet entretien préliminaire, déclarait en avoir oublié la teneur mais retenu la constante mauvaise humeur de son mari «que cela ennuyait profondément d'être questionné sur ce qu'il pensait dans sa jeunesse ». Le témoignage n'en demeure pas moins passionnant, poursuit-elle, notamment parce qu'il « montre un Lévi-Strauss passionné par le futur [et qui], à force d'anticiper, devançait parfois la pensée de ses collègues, qui ne le comprenaient pas. Mais c'est aussi grâce à cela que l'on parle encore de lui ».

Philippe ERIKSON 